\title{
Effect of inhaled and oral n-acetylcysteine on airway defense mechanism
}

Pappová L., ${ }^{1,2 \varpi}$ Kazimierová l., ${ }^{1,2}$ and Kocmálová M. ${ }^{1,2}$

\author{
${ }^{1}$ Comenius University in Bratislava, \\ Jessenius Faculty of Medicine in Martin \\ Biomedical Centre Martin, Martin, Slovak Republic \\ ${ }^{2}$ Comenius University in Bratislava, \\ Jessenius Faculty of Medicine in Martin, \\ Department of Pharmacology, Martin, Slovak Republic
}

Received 13 December, 2016, accepted 14 December, 2016

Abstract Aim: $\mathrm{N}$-acetylcysteine is the prototype of mucolytic agents. The aim of this study was to evaluate the acute and chronic effect of inhaled and oral $\mathrm{N}$-acetylcysteine on airway reactivity, cough reflex and ciliary beat frequency and parameters of mentioned defense mechanisms were assessed in physiological conditions.

Methods: An experiment was performed using healthy guinea pigs treated with inhaled $(0.6 \mathrm{M} ; 5 \mathrm{~min})$ and oral $\mathrm{N}$-acetylcysteine $(20 \mathrm{mg} / \mathrm{kg})$, administrated either acutely as a single dose or chronically during 7 days. The cough reflex and specific airway resistance were assessed by in vivo method, using a double chamber plethysmograph box. The ciliary beat frequency was evaluated in in vitro conditions on tracheal brushed samples using light microscope coupled to high speed video camera.

Results: Inhaled and oral $\mathrm{N}$-acetylcysteine, either administrated as a single dose or during 7 days, have shown a tendency to decrease sensitivity of the cough reflex and increase the airway reactivity. Acute administration of inhaled and oral $\mathrm{N}$-acetylcysteine had no statistically relevant effect on the ciliary beat frequency, whereas chronic administration of both inhaled and oral $\mathrm{N}$-acetylcysteine led to a marked reduction in the ciliary beat frequency.

Conclusion: Chronic administration of oral and inhaled $\mathrm{N}$-acetylcysteine had a negative impact on the ciliary beat frequency, which represents one of the key factors determining the rate of mucociliary clearance. Thus, administration of $\mathrm{N}$-acetylcysteine is less likely to increase the expulsion of mucus by ciliary movement. In addition, the observed tendency of inhaled and oral $\mathrm{N}$-acetylcysteine to increase the airway reactivity may limit its use in conditions with severe airflow obstruction.

Keywords $\quad N$-acetylcysteine-mucus clearance-ciliary beat frequency-airway reactivity

\section{INTRODUCTION}

Airway mucus hypersecretion is one of the prominent features of severe respiratory diseases. Pharmacological approach for relieving mucus accumulation in airways currently involves several classes of agents, including mucolytics. Mucolytics have gained importance as the drugs that can degrade the mucin polymers of mucus gel, and by reducing the viscosity and elasticity of mucus are thought to increase the mucus expulsion, either by ciliary movement or cough reflex (Rogers, 2007). Best known of these agents is $\mathrm{N}$-acetylcysteine (NAC). Although, it was introduced as, and it is still considered to be a mucolytic agent, this activity up to date has not been well established. The doubt about its effectiveness in chronic respiratory diseases arises from the uncertainties about the mechanism of action and controversial results of long-term clinical trials (Seagrave et al., 2012). Actually, none of the current recommendations for the treatment of chronic obstructive disease (GOLD, 2016) support the use of mucolytic agents as a part of the standard therapy due to lack of evidence. Moreover, several studies have demonstrated a dose dependent effect of NAC on the viscoelastic properties of secretion in vitro as well as after inhaled administration, but this effect is not seen when given orally, which may be associated with poor excretion of NAC into the airway lumen after oral administration (Fuloria \& Rubin, 2000). Nevertheless, some published evidence suggests, that oral NAC may improve pulmonary function in selected patients with chronic 
lung disease, but observed clinical benefit is more likely due to the antioxidant properties. On the contrary, there is no data that supports the clinical use of inhaled NAC, as it may cause bronchospasm (Rubin, 2014).

In this study, we centred our attention on the role of NAC in modulation of mucus clearance. Besides the well- established mucolytic activity, we were interested if oral and inhaled NAC also have the ability to affect the mucus clearance, directly acting on ciliary beat frequency (CBF) as one of the key regulator of the mucociliary clearance rate (Braiman \& Priel, 2008), and cough sensitivity. These parameters were evaluated in physiological conditions to avoid the indirect impact of other mentioned $\mathrm{N}$-acetylcysteine activities (antioxidant) on CBF or cough sensitivity. Moreover, we also addressed the possible effect of $\mathrm{N}$-acetylcysteine on airway reactivity, as it has been shown that inhaled $\mathrm{N}$-acetylcysteine may cause a bronchospasm, and thus, may worsen the airway obstruction (Reinero et al., 2011).

\section{MATERIAL AND METHODS}

The experiment was approved by the Institutional Ethics Committee of Jessenius Faculty of Medicine (permission IRB 00005636). All experimental procedures were performed according Slovakian and European Community regulations for the use of laboratory animals and guidelines on animal welfare (decision No. 1249/2013). Healthy adult male TRIKstrain guinea pigs were purchased from the accredited breeding facility, from the Department of Experimental Pharmacology, Slovak Academy of Sciences, Dobrá Voda, Slovakia (SKCH24011). Animals were housed under the control conditions with free access to food and water.

In the experiment, the commercially available product of N-acetylcysteine (ACC inject; sol. inj.) was used. Other chemicals such as citric acid and bronchoconstrictor mediator (histamine), were obtained from Sigma Aldrich Chemicals (St. Louis, MO, US).

\section{Experimental groups}

The experiment was carried out using healthy male guinea pigs weighting 300-400 g. The animals were randomly divided into experimental groups comprising 10 animals per group $(n=10)$. Animals assigned to the therapeutic groups were treated with inhaled ( $0.6 \mathrm{M} ; 5 \mathrm{~min})$ and oral NAC ( $20 \mathrm{mg} / \mathrm{kg})$, administrated either acutely as a single dose or chronically during 7 days. The guinea pigs in control group received only water vehiculum $\left(1 \mathrm{~mL} . \mathrm{kg}^{-1}\right)$ in the case of oral NAC administration, or the animals were exposed to saline aerosol instead of NAC aerosol. NAC solution was aerosolized by jet nebulizer (PARI jet nebuliser, Paul Ritzau, Pati-Werk GmbH, Germany, output $51 . \mathrm{s}^{-1}$, particles mass median diameter 1,2 $\mu \mathrm{m}$ ) delivering the aerosol of drug to head chamber of double body plethysmograph (HSE type 855, Hugo Sachs Electronic, Germany), where the animals were placed.

\section{The evaluation of cough reflex in vivo}

Healthy conscious guinea pigs were individually placed in a double chamber plethysmograph box (HSE type 855, Hugo Sachs Electronic, Germany) and cough evaluation was performed according to the method described by Franova et al. (Franova et al., 2013). Briefly, the cough reflex was provoked chemically, by the exposure of animals to citric acid aerosol in a time interval of three minutes, during which the number of cough efforts were counted. Citric acid solution at a concentration of $0.3 \mathrm{~mol} / \mathrm{L}$ was aerosolized by jet nebulizer (PARI jet nebuliser, Paul Ritzau, Pati-Werk GmbH, Germany, output $51 . \mathrm{s}^{-1}$, particles mass median diameter 1,2 $\mu \mathrm{m}$ ). Sudden enhancement of expiratory flow during coughing was detected by pneumotachograph connected to the nasal chamber of the double body plethysmograph. In accordance with ERS guidelines, cough effort was defined as sudden PC-recorded enhancement in expiratory airflow, which was simultaneously accompanied by a characteristic cough sound and movement. Sound and movement typical for cough reflex were evaluated and recognised by two trained observers and compared using video recordings (Morice et al., 2007).

\section{The evaluation of airway smooth muscle reactivity in vivo}

Airway smooth muscle reactivity was evaluated on conscious animals using a double chamber plethysmograph box (HSE type 855, Hugo Sachs Electronic, Germany). For the assessment of airway reactivity, the values of specific airway resistance (sRAW) were used. As per Pennoc, sRaw is a parameter calculated from the phase shift between nasal and thoracic respiratory flows, using the HSE respiratory software PULMODYN PENNOCK. Changes in the thoracic and nasal airflow were provoked according to a method described by Kazimierová et al. (Kazimierová et al., 2015). Briefly, the animals were exposed for thirty seconds to histamine aerosol at concentration $10^{-6} \mathrm{~mol} / \mathrm{L}$. An interval of $1 \mathrm{~min}$ was provided between the exposure to histamine and sRaw measurement, during which fresh air was insufflated into the nasal chamber.

\section{The evaluation of ciliary beat frequency in vitro}

After sacrificing the animals, the small window was dissected in precisely cleaned upper part of the trachea, in order to expose the tracheal epithelium for brushing the collection of ciliated cells by cytological brush. Acquired material was resuspended on a heated microscope slide into a drop of warm saline solution $\left(36,5^{\circ} \mathrm{C} \pm 0,5\right)$ and obscured by a cover slide. The undisrupted strips of ciliated epithelium with the presence of beating cilia were selected using an inverted phase contrast microscope (Zeiss Aixo vert. A1; carl Zeiss AG, Göttingen, Germany) and recorded by high speed video camera (Basler A504kc; Adept Turnkey Pty Ltd, Brookvale, Australia) with the 
frame rate $256-512$ frames per second. The recorded short video sequences of beating regions, approximately 10 video sequences per sample, were analysed by the LabwiewTM software generating ciliary regions of interest (ROI). For every $\mathrm{ROI}$, the median of ciliary beat frequency was calculated and used as an evaluation parameter. The final value of the ciliary beat frequency (CBF) expressed in $\mathrm{Hz}$, was an average of ten median values obtained from each specimen.

\section{Statistical analysis}

All results are represented as means \pm SEM. Statistical analysis was performed using one-way analysis of variance ANOVA. A $P$ value of less than 0.05 was taken as a threshold for statistical significance.

\section{RESULTS}

\section{Cough reflex}

The changes in cough reflex, evaluated in 'in vivo', were assessed before drug administration to obtain a control group. The effect of oral and inhaled NAC on cough reflex was recorded 2 hours after the single dose and 2 hours after the last dose of a 7-day treatment. As the evaluation parameter, the number of cough efforts induced by citric acid inhalation were used. Inhaled and oral NAC, either administrated as a single dose or during 7 days, showed a tendency to decrease the number of chemically induced cough efforts, however these results were not statistically significant (Table 1).

\section{Airway reactivity}

The airway contraction under 'in vivo' conditions was provoked by histamine inhalation, and as an evaluation parameter, the values of specific airway resistance were used. The measurement of changes in specific airway resistance was realized before and 2 hours after the oral and inhaled
NAC administration. Both, single and 7-day treatments with oral and inhaled NAC caused a small increase in the values of specific airway resistance. However, none of the NAC administrations (neither oral nor acute therapy) showed any statistically relevant bronchoconstrictor activity (Table 1).

\section{Ciliary beat frequency}

Oral and inhaled NAC effect on ciliary movement was evaluated 'in vitro' by recording the changes in CBF. Acute administration of oral and inhaled NAC had no significant effect on ciliary movement, although inhaled acute NAC administration has shown the tendency to supress CBF slightly in comparison to the acute administration of oral NAC, after which no effect on CBF was observed. On the contrary, chronic administration of both, inhaled and oral NAC, significantly reduced CBF (Fig. 1).

\section{DISCUSSION}

Airway surface fluid, composed of mucus gel layer and periciliary sol fluid, forms an important part of the defense mechanisms of the airways. The upper mucus layer acts as a medium in which the inhaled foreign particles are trapped, whereas the less viscous periciliary fluid maintains the gel layer at the optimal distance from the airway epithelium and provides an ideal environment for ciliary beating. To protect the airway epithelium, the mucus is constantly removed by means of beating cilia and replenished by new one in a process called mucociliary transport (MCT). MCT represents one of the most important mucus clearance mechanisms; its rate depends on the viscoelastic properties of mucus layer, depth of periciliary fluid and on the kinetic parameters of beating cilia. The depth and composition of airway surface fluid are regulated by mucin secretion and by the hydration, mediated through the active ion transport across the airway epithelium (Fahy \& Dickey, 2010). Some studies have demonstrated that $\mathrm{NAC}$, in addition to exert the mucolytic activity, may improve the hydration of airways through the downregulation of the
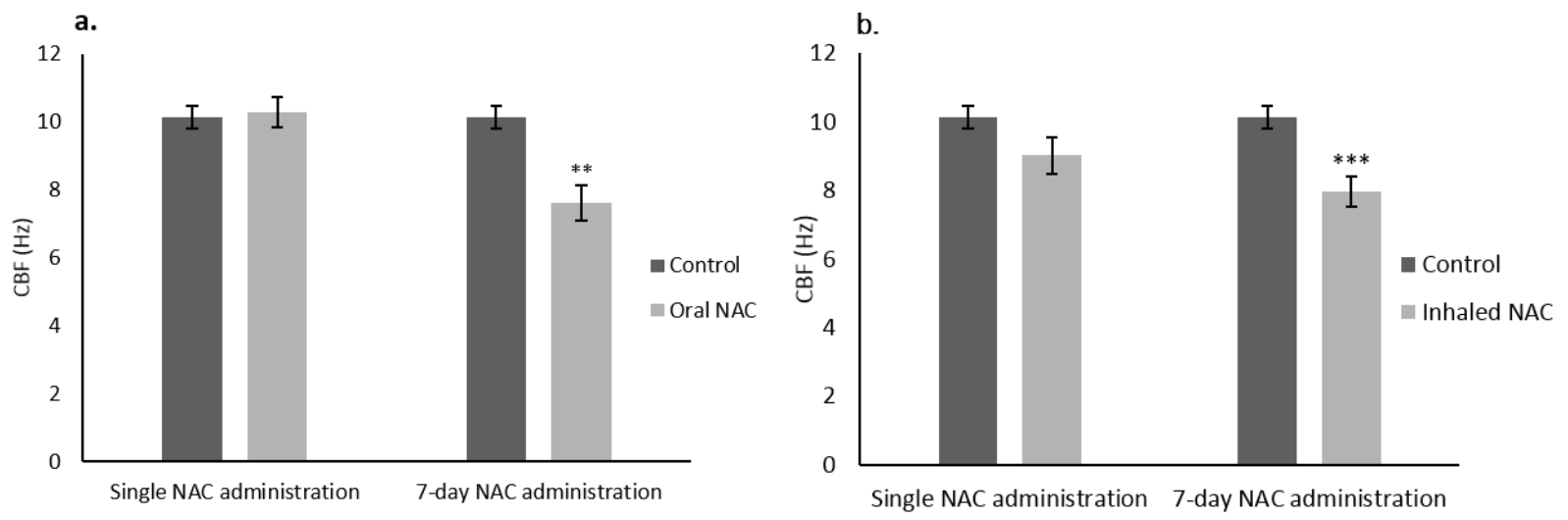

Figure 1. Changes in ciliary beat frequency. Changes in ciliary beat frequency (CBF) induced by oral (a.) and inhaled (b.) $N$-acetylcysteine (NAC) administrated as a single dose or as a 7-day treatment. Statistical significance: ${ }^{* *} p<0,01 \mathrm{vs}$. control; ${ }^{* * *} p<0,001 \mathrm{vs}$. control (one-way ANOVA and Bonferroni post hoc test). 
Table 1. Changes in cough efforts and specific airway resistance. Changes in number of cough efforts and specific airway resistance (sRaw) after chronic (7 days) and acute administration of inhaled (inh.) and oral (p.o.) N-acetylcysteine (NAC). Data are expressed as the means \pm SEM. Statistical analysis: Student's t-test.

\begin{tabular}{|c|c|c|c|c|c|c|c|c|}
\hline & \multicolumn{2}{|c|}{ NAC inh. acutely } & \multicolumn{2}{|c|}{ NAC inh. 7 days } & \multicolumn{2}{|c|}{ NAC p.o. acutely } & \multicolumn{2}{|c|}{ NAC p.o. 7days } \\
\hline & $\begin{array}{l}\text { Before ad- } \\
\text { ministration }\end{array}$ & $\begin{array}{l}\text { After admin- } \\
\text { istration }\end{array}$ & $\begin{array}{l}\text { Before ad- } \\
\text { ministration }\end{array}$ & $\begin{array}{l}\text { After admin- } \\
\text { istration }\end{array}$ & $\begin{array}{l}\text { Before ad- } \\
\text { ministration }\end{array}$ & $\begin{array}{l}\text { After admin- } \\
\text { istration }\end{array}$ & $\begin{array}{l}\text { Before ad- } \\
\text { ministration }\end{array}$ & $\begin{array}{l}\text { After admin- } \\
\text { istration }\end{array}$ \\
\hline $\begin{array}{l}\text { Number } \\
\text { of cough } \\
\text { efforts }\end{array}$ & $\begin{array}{c}7,875 \pm \\
1,008\end{array}$ & $6,000 \pm 1,402$ & $\begin{array}{c}8,500 \pm \\
1,880\end{array}$ & $\begin{array}{c}6,250 \pm \\
1,333\end{array}$ & $\begin{array}{c}8,000 \pm \\
1,633\end{array}$ & $\begin{array}{c}6,571 \pm \\
1,974\end{array}$ & $\begin{array}{c}8,000 \pm \\
0,724\end{array}$ & $\begin{array}{c}7,428 \pm \\
0,841\end{array}$ \\
\hline sRaw & \multirow{2}{*}{$\begin{array}{c}6,470 \pm \\
1,119\end{array}$} & \multirow{2}{*}{$\begin{array}{c}8,728 \pm \\
1,452\end{array}$} & \multirow{2}{*}{$\begin{array}{c}5,483 \pm \\
1,695\end{array}$} & \multirow{2}{*}{$\begin{array}{l}6,567 \pm \\
2,335\end{array}$} & \multirow{2}{*}{$\begin{array}{c}5,331 \pm \\
2,021\end{array}$} & \multirow{2}{*}{$\begin{array}{l}7,528 \pm \\
2,442\end{array}$} & \multirow{2}{*}{$\begin{array}{c}8,069 \pm \\
2,061\end{array}$} & \multirow{2}{*}{$\begin{array}{c}11,182 \pm \\
2,238\end{array}$} \\
\hline$(\mathrm{ml} / \mathrm{s})$ & & & & & & & & \\
\hline
\end{tabular}

epithelial sodium channels and the enhancement of chloride efflux into the airway lumen (Rochat et al., 2004; Varelogianni et al., 2010). However, both mentioned effects may be beneficial in the regulation of MCT, and NAC does not seem to improve MCT. Seagrave et al. attributed the observed decline in MCT rate to excessive reduction of mucus viscosity induced by NAC, which may result in disruption of effective coupling between the mucus and beating cilia (Seagrave et al., 2012). Although both periciliary fluid and mucus layer are important components of MCT, the reduction in ciliary movement can have a great impact on MCT. Thus, we focused our attention to evaluate the direct effect of NAC on $C B F$, which represents the driving force for MCT (Braiman \& Priel, 2008). According to our study, the decrease in MCT may be associated with the negative effect of NAC on ciliary movement. We recorded significant reduction in $\mathrm{CBF}$ after the 7-day treatment with inhaled as well as oral NAC. Acutely, slight decrease in CBF was observed only after NAC inhalation, whereas acute oral NAC therapy had no effect on ciliary movement.

In the case of mucociliary dysfunction, the cough becomes the most important mechanism for mucus clearance (Munkholm \& Mortensen, 2014). Regarding the negative effect of NAC on $C B F$, the suppression of cough reflex sensitivity would lead to considerable retention of mucus in the airways. For mentioned reason, it is important to know the effect of NAC on cough reflex sensitivity. Although, chronic and acute administration of oral NAC has shown a tendency to decrease the number of cough efforts slightly, these results were not statistically relevant. However, NAC, by the mucolytic action, may decrease the mucus adhesivity to airway epithelium, facilitating the mucus expulsion by cough (Rubin, 2010). No data convincingly demonstrates that any classic mucolytic agent including the NAC improves the ability to expectorate mucus (Rubin, 2007).
Furthermore, since the significant airflow limitation due to the mucus accumulation may be worsened by airway narrowing (Rogers, 2007), the determination of the NAC effect on the reactivity of bronchial smooth muscle formed part of this study. Unfortunately, regardless of the duration or route of administration, NAC induced a small increase in the airway reactivity provoked by histamine inhalation in vivo. Although this rise in airway reactivity was insignificant, it can be considerable in some hyper-reactive airway diseases, as demonstrated in the study carried out on cats with experimental asthma (Reinero et al., 2011).

In conclusion, we can summarize, that in our study we did not record any significant difference between oral and inhaled NAC administration. Chronic administration by both routes led to a significant decrease in $\mathrm{CBF}$, which may have a great impact on mucus accumulation. Although in our physiological conditions, NAC negatively affected mucus clearance, in pathological conditions, its mild anti-inflammatory and antioxidant activity may be of benefit if combined with bronchodilators, which also possess ciliostimulatory activity (Pappová et al., 2016).

\section{ACKNOWLEDGEMENT}

Work was supported: APVV 0305-12, VEGA 1/0165/14 a MZ 2012/35- UK, CERK II, UK/62/2016; by the project 'Biomedical Centre Martin' ITMS: 26220220187 'We support research activities in Slovakia/ The project is co-financed from EU sources.' 
[1] Braiman A, Priel Z. Efficient mucociliary transport relies on efficient regulation of ciliary beating. Respir. Physiol. Neurobiol. 2008; 163: 202-207.

[2] Fahy JV, Dickey BF. Airway mucus function and dysfunction. N. Engl. J. Med. 2010; 363: 2233-2247.

[3] Franova S, Joskova M, Sadlonova V, Pavelcikova D, Mesarosova L, Novakova E, Sutovska M. Experimental model of allergic asthma. Adv Exp Med Biol. 2013; 756:49-55

[4] Fuloria M, Rubin BK. Evaluating the efficacy of mucoactive aerosol therapy. Respir. Care 2000; 45: 868-873.

[5] GOLD. Global Strategy for the Diagnosis, Management and Prevention of COPD, Global Initiative for Chronic Obstructive Lung Disease (GOLD) 2015.

[6] Kazimierová I, Jošková $M$, Pecháňová O, Šutovská $M$, Fraňová S. Effects of provinol and its combinations with clinically used antiasthmatics on airway defense mechanisms in experimental allergic asthma. Adv Exp Med Biol. 2015;838:27-34.

[7] Morice AH, Fontana GA, Belvisi MG, Birring SS, Chung KF, Dicpinigaitis PV, Kastelik JA, McGarvey LP, Smith JA, Tatar M et al. ERS guidelines on the assessment of cough. Eur. Respir. J. 2007; 29: 1256-1276.

[8] Munkholm M, Mortensen J. Mucociliary clearance: pathophysiological aspects. Clin. Physiol. Funct. Imaging 2014; 34: 171-177.

[9] Reinero CR, Lee-Fowler TM, Dodam JR, Cohn LA, DeClue AE, Guntur VP. Endotracheal nebulization of $\mathrm{N}$-acetylcysteine increases airway resistance in cats with experimental asthma. J. Feline Med. Surg. 2011; 13: 69-73.
[10] Rogers D. Mucoactive agents for airway mucus hypersecretory diseases. Respir. Care. 2007; 52: 1176-93.

[11] Rochat T, Lacroix J-S, Jornot L. N-acetylcysteine inhibits $\mathrm{Na}+$ absorption across human nasal epithelial cells. J. Cell. Physiol. 2004; 201: 106-116.

[12] Rubin BK. Secretion properties, clearance, and therapy in airway disease. Transl. Respir. Med. 2014;2: 6.

[13] Rubin BK. The role of mucus in cough research. Lung. 2010; 188 (1 Suppl): S69-72.

[14] Seagrave J, Albrecht HH, Hill DB, Rogers DF, Solomon G. Effects of guaifenesin, $\mathrm{N}$-acetylcysteine, and ambroxol on MUC5AC and mucociliary transport in primary differentiated human trachealbronchial cells. Respir. Res. 2012;13: 98.

[15] Varelogianni G, Oliynyk I, Roomans GM, Johannesson M. The effect of $\mathrm{N}$-acetylcysteine on chloride efflux from airway epithelial cells. Cell Biol. Int. 2010; 34: 245-252.

[16] Rubin BK. Mucolytics, expectorants, and mucokinetic medications. Respir. Care. 2007; 52: 859-865.

[17] Pappová L, Jošková $M$, Kazimierová I, Šutovská $M$, Fraňová S. Combination Therapy with Budesonide and Salmeterol in Experimental Allergic Inflammation. Adv. Exp. Med. Biol. 2016: 935: 25-34. 